\title{
The triggering role of Clostridioides difficile infection in relapsed IBD outpatients
}

\author{
| Anita Bálint MD', Zoltán Szepes MD PhD¹, Mónika Szűcs², Klaudia Farkas MD PhD¹, Edit Urbán PhD³, Ferenc Nagy MD PhD', \\ Renáta Bor MD', Mariann Rutka MD¹, Ágnes Milassin MD', Tamás Molnár MD PhD'1 \\ ${ }^{1}$ University of Szeged, $1^{\text {st }}$ Department of Medicine, Szeged, Hungary \\ ${ }^{2}$ University of Szeged, Department of Medical Physics and Informatics, Szeged, Hungary \\ ${ }^{3}$ University of Szeged, Institute of Clinical Microbiology, Szeged, Hungary \\ Correspondence: balint.anita@med.u-szeged.hu
}

Although the exact aetiology of inflammatory bowel disease (IBD) is unknown, one hypothesis suggests that the inflammation may be the consequence of an altered or pathogenic microbiota in a genetically susceptible host. The aim of this study was to assess the frequency of enteral infections in patients with relapse of IBD, and to evaluate the clinical utility of faecal calprotectin (FC) and faecal matrixmetalloproteinase-9 (MMP-9) in the differential diagnosis of relapses with different origins, and to determine the recurrence rate of Clostridioides difficile (C. difficile), the hospitalisation and colectomy rate among C. difficile positive IBD patients at the end of 4 years follow-up period.

Methods: In this prospective, "real life" study clinical data, serum and stool samples were assessed.

Results: Overall, 135 outpatients with IBD were enrolled [91 IBD patients who relapsed and 44 subjects in clinical remission (control group)]. C. difficile A/B toxins were detected in $42.2 \%$ of all cases. Candida was presented in $9.9 \%$ among the enrolled subjects. We found significant difference between FC and MMP-9 values in patients in relapse and remission, but not in C. difficile positive and negative cases. Our results revealed an association between previous antibiotic use and the rate of toxigenic $C$. difficile. Toxigenic $C$. difficile positivity recurrence rate was $4.4 \%$. Hospitalisation during follow-up due to IBD was $45.4 \%$ and $35 \%$ in C. difficile positive and negative group, respectively. Value of FC and MMP-9 did not predict the need of hospitalisation.

Conclusions: The occurrences of toxigenic $C$. difficile and Candida positivity were excessively high in our patients in an acute relapse, which suggests the importance of intestinal microbiota in IBD. FC and MMP-9 has no diagnostic value to differentiate between infection-induced and natural relapse. In our study was confirmed that hospitalisation rate was higher in C. difficile positive cases, but we did not find any relationship on long-term period.

KEYWORDS: Clostridioides difficile, ulcerative colitis, Crohn's disease, faecal calprotectin, matrix metalloproteinase-9

\section{Introduction}

The course of the inflammatory bowel diseases (IBD: Crohn's disease - CD - and ulcerative colitis - UC) are chronic or intermittent and coloured by multiple flare-ups, despite long-term maintenance treatment in about half of the patients $(1,2)$. Just as with the initial manifestation of $\mathrm{IBD}$, the factors which cause subsequent relapses are also ambiguous in most cases; however, an infective agent may play a role in both the manifestation and the relapse (3).
Some animal experiments suggest a role is played by bacteria in the pathogenesis of IBD: interleukin-10 knockout, germ-free mice do not develop colitis; however, interleukin-2-deficient mice develop spontaneous colitis after Escherichia coli exposure, but not with Bacteroides vulgatus exposure (4). Although the aetiology of IBD has not been unequivocally clarified, an altered intestinal immune response due to the interaction of several environmental and genetic factors is observable, which may lead to inadequate gut flora compound and function, thus 
making the intestine vulnerable to superinfections like the infections caused by toxigenic Clostridioides difficile (C. difficile) $(5,6,7)$. C. difficile infections came to the front since epidemiological data showed high prevalence of toxinproducing isolates $(8,9)$ among IBD patients. Current data suggest that in patients with CD or UC, infections caused by this anaerobic bacterium occur more frequently than in the general population (10). The significance of toxigenic C. difficile positivity manifests not only in its increasing incidence, growing antibiotic resistance and severe disease course, but also in the magnitude of the infections, which also leads to high health care costs. Expansion of $C$. difficile infections is more pronounced in IBD patients; moreover, its prevalence has been reported in 5 to $19 \%$ in patients with active disease $(11,12)$. According to previous studies, the rate of $C$. difficile infection is approximately 4-5 times greater than in non-IBD patients $(13,14)$. However, most of studies are retrospectively performed.

The usual diagnostic tools in case of a relapse of IBD consist of faecal microbiological examination and an evaluation of inflammatory biochemical and stool biomarkers. A simply and quickly performing marker would be useful as strong point in the differentiation of an infective origin or exacerbation. Faecal calprotectin (FC) and matrix metalloproteinase-9 (MMP-9) are markers that correlate with disease activity. FC is a neutrophil leukocyte-derivate protein eligible for distinguishing IBD from functional disorders (15). In vitro resistance to degradation allows faecal samples to be assayed for reliable calprotectin determination. FC has a high sensitivity in the determination of IBD activity; however, elevated levels were also shown in intestinal infections, tumours and colon polyps, therefore its specificity is less favourable. MMP-9 is a Zn-binding neutral proteinase produced by polymorphonuclear cells. MMP-9 is one of the major contributors to the breakdown and reconstruction of the extracellular matrix (16). Faecal MMP-9 and FC in UC patients is an excellent marker of disease activity and shows significant correlation with clinical and endoscopic scores (17).

The objective of this study was to prospectively assess the prevalence of enteral infections (especially toxigenic C. difficile and Candida sp.) among our outpatients with IBD in relapse. Patients in remission were examined as a control group. In addition, our secondary endpoint was to estimate the utility of clinical and differential diagnoses of FC and MMP-9 in cases of both with infection and without infection. The tertiary endpoint was to assess the long-term outcome of $C$. difficile infection in IBD patients. We aimed to determine the recurrence rate of $C$. difficile, the hospitalisation and colectomy rate among $C$. difficile positive IBD patients at the end of 4 years follow-up period.

\section{Patients and methods}

\section{Patient selection}

91 IBD patients with symptoms of relapse were enrolled in our study with 44 control IBD subjects in clinical remission from September, 2012 to July, 2013. All of them were outpatients at the 1st Department of Medicine,
Szeged, Hungary. The medical data of patients were collected prospectively. Clinical data, activity indexes, faecal specimens and serum samples were analysed of 91 IBD patients who manifested worsening symptoms - indicating a potential relapse - and of 44 IBD patients in remission. Blood samples were taken from all patients for the determination of CRP level (C-reactive protein), platelet and leukocyte count, serum iron level and haemoglobin level. Faecal samples from every subject were sent to the microbiological laboratory of the Institute of Clinical Microbiology, University of Szeged. The clinical activity of CD and UC were assessed using the Crohn's Disease Activity Index (CDAI) and with a partial Mayo Score (pMayo), respectively. Relapse was defined as $\geq 150$ points and/or an increase of $\geq 80$ points in the CDAl in the case of CD and $\geq 2$ points in the pMayo score in the case of UC. Immuno-

\section{Table 1. Clinical characteristics of patients at} the time of enrolment

\begin{tabular}{|c|c|c|}
\hline & $\begin{array}{l}\text { Relapsing } \\
\text { group } \\
(n=91)\end{array}$ & $\begin{array}{l}\text { Control } \\
\text { group } \\
(n=44)\end{array}$ \\
\hline $\begin{array}{l}\text { Gender (male/female) } \\
\text { No. of patients }\end{array}$ & $43 / 48$ & $26 / 18$ \\
\hline $\begin{array}{l}\text { Age } \\
\text { Years, mean (min-max) }\end{array}$ & $\begin{array}{c}36.8 \\
(16 \text { to } 79)\end{array}$ & $\begin{array}{c}40 \\
(19 \text { to } 75)\end{array}$ \\
\hline $\begin{array}{l}\text { UC/CD } \\
\text { No. of patients }\end{array}$ & $49 / 42$ & 25/19 \\
\hline \multicolumn{3}{|c|}{$\begin{array}{l}\text { Disease location (based on Montreal classification of } \\
\text { IBD) }\end{array}$} \\
\hline L1 & 15 & 6 \\
\hline L2 & 7 & 6 \\
\hline L3 & 20 & 7 \\
\hline E1 & 11 & 8 \\
\hline E2 & 20 & 6 \\
\hline E3 & 18 & 11 \\
\hline $\begin{array}{l}\text { Disease duration (years) } \\
\text { Years, mean (min-max) }\end{array}$ & $\begin{array}{c}6.9 \\
(0 \text { to } 26)\end{array}$ & $\begin{array}{c}10.9 \\
(0 \text { to } 46)\end{array}$ \\
\hline $\begin{array}{l}\text { Appendectomy } \\
\text { No. of patients }\end{array}$ & 4 & 1 \\
\hline $\begin{array}{l}\text { Smoking } \\
\text { No. of patients }\end{array}$ & 17 & 5 \\
\hline $\begin{array}{l}\text { Extraintestinal manifestation } \\
\text { No. of patients }\end{array}$ & 36 & 9 \\
\hline $\begin{array}{l}\text { Immunosuppression } \\
\text { No. of patients }\end{array}$ & 46 & 25 \\
\hline $\begin{array}{l}\text { Gastricacid-suppressant } \\
\text { agent } \\
\text { No. of patients }\end{array}$ & 25 & 8 \\
\hline $\begin{array}{l}\text { Antibiotic use in previous } \\
3 \text { months } \\
\text { No. of patients }\end{array}$ & 18 & 4 \\
\hline $\begin{array}{l}\text { Previous C. difficile positivity } \\
\text { No. of patients }\end{array}$ & 23 & 7 \\
\hline
\end{tabular}


suppression was defined by Consensus of the European Crohn's and Colitis Organisation (ECCO) (3). Data of the patients regarding smoking status, previous appendectomy, perianal involvement, the presence of extraintestinal manifestations of IBD, previous antibiotic use and concomitant medications were collected from each subject. The clinical characteristics of the patients are presented in Table 1.

\section{Microbiological examination}

A microbiological analysis for the presence of enteric pathogens (including toxigenic C. difficile, Campylobacter spp., Salmonella spp., Shigella spp., Yersinia spp., Candida spp. and in reasonable cases viruses and parasites) was carried out at the Institute of Clinical Microbiology, Szeged, Hungary. Laboratory diagnosis of toxigenic C. difficile was based on ESCMID guideline (18): faecal samples were tested for the presence of glutamate dehydrogenase (GDH) and toxin A/B using the QUIK CHEK COMPLETE (TechLab). Samples with a GDH-positive, but toxin $A / B$ negative results were further tested with toxigenic culture method. Toxigenic culture is one of reference method for diagnosing C.difficile infection. The basis of this method is isolation of $C$. difficile and testing the toxin production in vitro by a sensitive $A / B$ toxin detection method (18).

\section{Measurement of faecal calprotectin and MMP-9} Samples for FC and MMP-9 determination were stored at $-20{ }^{\circ} \mathrm{C}$ until analysed. Faecal specimens were thawed and prepared for a calprotectin assay as described by the manufacturer. FC levels were measured by

\section{Table 2. Inflammatory biomarkers and clinical activity indices of IBD patients at the time of enrolment}

\begin{tabular}{|c|c|c|}
\hline & $\begin{array}{l}\text { Relapsing } \\
\text { group }(\mathrm{n}=91)\end{array}$ & $\begin{array}{l}\text { Control } \\
\text { group }(n=44)\end{array}$ \\
\hline $\begin{array}{l}\text { CDAI } \\
\text { mean (min-max) }\end{array}$ & $\begin{array}{c}219.6(105 \text { to } \\
450)\end{array}$ & $\begin{array}{c}60.7 \\
\text { (0 to 127) }\end{array}$ \\
\hline $\begin{array}{l}\text { pMayo Score } \\
\text { mean (min-max) }\end{array}$ & $\begin{array}{c}5.2 \\
(2 \text { to } 9)\end{array}$ & $\begin{array}{c}0.6 \\
\text { (0 to } 2)\end{array}$ \\
\hline $\begin{array}{l}\mathrm{FC}(\mu \mathrm{g} / \mathrm{g}) \\
\text { median (min-max) }\end{array}$ & $\begin{array}{c}640 \\
(29 \text { to } 14000)\end{array}$ & $\begin{array}{c}79 \\
\text { (29 to } 860)\end{array}$ \\
\hline $\begin{array}{l}\text { Fecal MMP-9 (ng/mL) } \\
\text { mean (min-max) }\end{array}$ & $\begin{array}{c}11.4 \\
\text { (0 to } 168.8)\end{array}$ & $\begin{array}{c}5.6 \\
\text { (0 to 23.2) }\end{array}$ \\
\hline $\begin{array}{l}\text { CRP (mg/L) } \\
\text { mean (min-max) }\end{array}$ & $\begin{array}{c}23.1 \\
(1 \text { to } 202.6)\end{array}$ & $\begin{array}{c}6.5 \\
\text { (1 to } 40.8)\end{array}$ \\
\hline $\begin{array}{l}\text { Leucocytes (G/L) } \\
\text { mean (min-max) }\end{array}$ & $\begin{array}{c}9.8 \\
\text { (3.8 to } 90.6)\end{array}$ & $\begin{array}{c}7.4 \\
\text { (3.6 to 15.1) }\end{array}$ \\
\hline $\begin{array}{l}\text { Thrombocytes (G/L) } \\
\text { mean (min-max) }\end{array}$ & $\begin{array}{c}326 \\
\text { (88 to 657) }\end{array}$ & $\begin{array}{c}292.7 \\
\text { (125 to } 602)\end{array}$ \\
\hline $\begin{array}{l}\text { Serum iron ( } \mu \text { mol/L) } \\
\text { mean (min-max) }\end{array}$ & $\begin{array}{c}11.5 \\
\text { (1.9 to } 25.3)\end{array}$ & $\begin{array}{c}15.1 \\
(4.3 \text { to } 33.1)\end{array}$ \\
\hline $\begin{array}{l}\text { Hematocrit (\%) } \\
\text { mean (min-max) }\end{array}$ & $\begin{array}{c}39 \\
\text { (21 to } 49)\end{array}$ & $\begin{array}{c}40 \\
\text { (33 to } 46)\end{array}$ \\
\hline
\end{tabular}

a quantitative lateral flow assay (Quantum Blue, Bühlmann Labortories, Switzerland). Samples for MMP-9 determination were thawed and prepared as described by the manufacturer. In a few words, one gram of the sample was diluted and homogenised in $4 \mathrm{ml}$ of an icecold buffer $(0.15 \mathrm{M} \mathrm{NaCl}+20 \mathrm{mM}$ Tris- $\mathrm{HCl}, \mathrm{pH}: 8.3)$. The suspension was then centrifuged at $1500 \mathrm{~g}$ for $10 \mathrm{~min}$ and the supernatant was recentrifuged at $10,000 \mathrm{~g}$ for $10 \mathrm{~min}$. The final supernatant was filtered and stored at $-20^{\circ} \mathrm{C}$ until analysed. MMP9 concentrations were determined by ELISA method (Quantikine MMP9 assay, R\&D System, UK).

\section{Statistical analysis}

The collected data was analysed statistically, using Pearson's chi-square test, Pearson's chi-square test with Yates' continuity correction and Wilcoxon rank sum test with continuity correction. $\mathrm{P}<0.05$ was considered as statistically significant. For the statistical analysis, SPSS15.0 (SPSS Inc., Chicago, IL, USA) was used.

\section{Ethical Considerations}

The study was approved by the Regional and Institutional Human Medical Biological Research Ethics Committee of the University of Szeged (ethical approval number: SZTE170/2011).

\section{Results}

\section{Infection Rates}

Out of the 135 enrolled patients (91 with relapse and 44 control), 74 subjects were diagnosed with UC and 61 with CD. Forty-nine UC and 42 CD patients participated in the relapse group. The number of UC and CD patients was 25 vs. 19 subjects in the control group (Table 1.). In the relapsing group the mean value of the Crohn's Disease Activity Index (CDAI) was 219.6 points (in the range of: 105 to 450 ) and the mean value of the pMayo score in the case of UC was 5.2 (in the range of: 3 to 9) points at the time of enrolment (Table 2.). The most frequent disease locations in the relapse cohort were left sided and pancolitis ( 20 and 17 subjects) in the case of UC, and pure ileal and the ileocolonic in the case of CD (15 and 20 subjects). Approximately half of the patients were immunosuppressed in the relapse group and also in the control group (Table 1. and 2.).

Toxigenic C. difficile or Candida spp. was identified in 53 of 91 faecal samples taken from relapsing patients; on the other hand, 11 of 44 patients had positive microbiological stool findings in the control group in remission $(p<0.001) .49$ participants with positivity of $C$. difficile $A / B$ toxins had been detected among the patients in relapse (53.8\%), while toxigenic C. difficile positivity was observed in 8 patients (18.2\%) in the remission group. Other microbiological findings in the relapse group were the presence of Candida species (10 patients) in all except one subject, who had Salmonella infection. Candida species occurred in 4 patients in the control group. In 7 cases we found simultaneous presence of toxigenic 
Figure 1. Infection rates among patients with relapse and remission of IBD at the time of enrolment

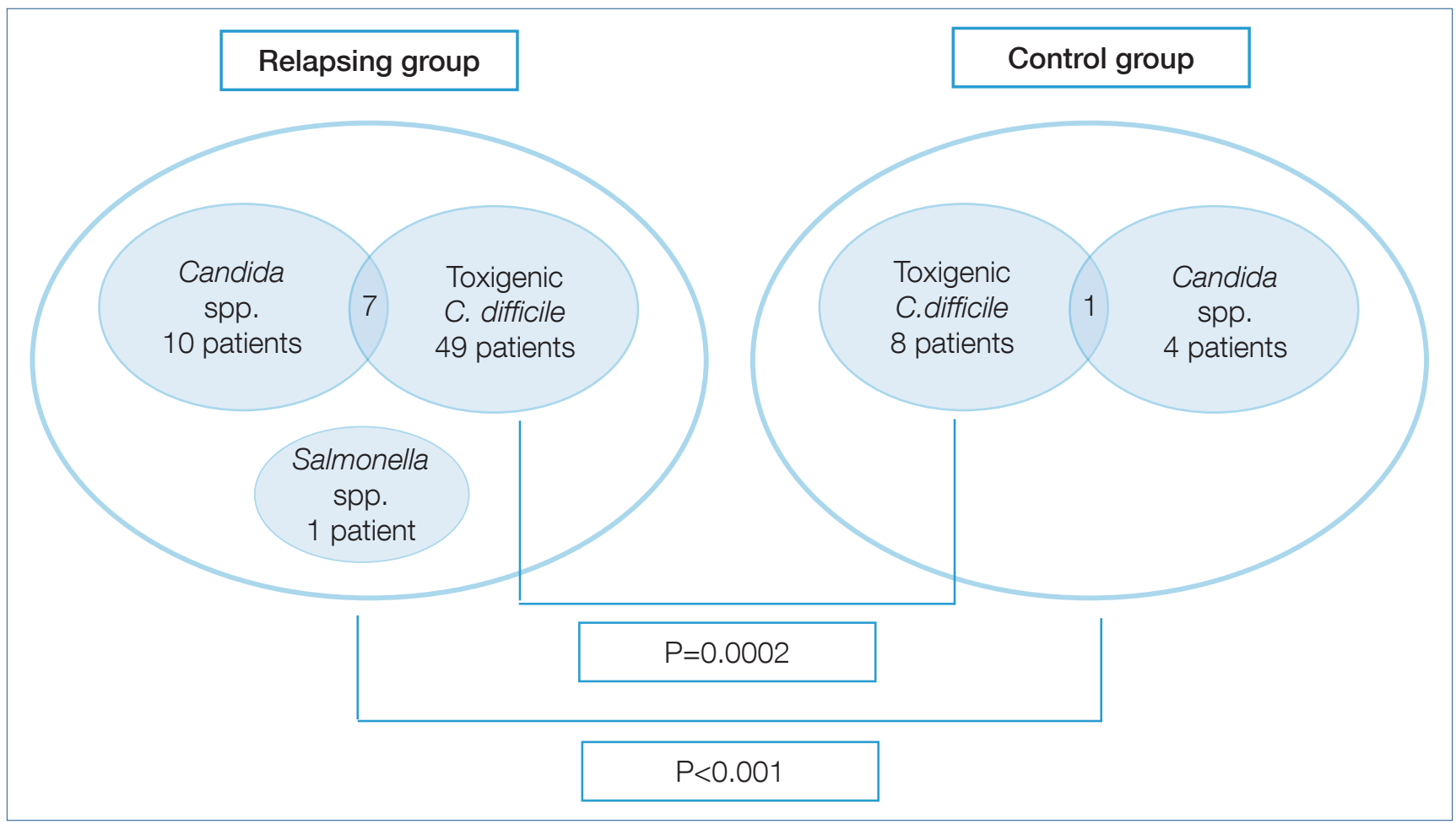

C. difficile and Candida sp. in relapse group, and in one case in the control group (Figure 1.).

A significant difference was revealed between the relapse and the control group regarding the positive cases of $C$. difficile $(P=0.0002)$. We found that relapse of IBD is a predicting factor for $C$. difficile positivity $(P=0.01) .23$ subjects in the relapse group had previous toxigenic $C$. difficile positivity in their medical history, although only 14 of the currently infected patients were positive in the past. Six patients had recurrent toxigenic $C$. difficile positivity in relapsing group during follow-up period. Seven of the control subjects had positive toxigenic C. difficile results previously, but only 2 of currently $C$. difficile-positive subjects had a medical history of $C$. difficile infections. We did not find a difference between $C D$ and UC regarding positive microbiological examination findings or toxigenic C. difficile positivity (29 subjects with UC and 26 with CD). There was no significant connection between disease extension, extraintestinal manifestations, perianal involvement, smoking, age, gender, disease duration, immunosuppression and gastricacid-suppressant agent use and toxigenic $C$. difficile positivity. Previous antibiotic use was $19.8 \%$ in the relapse group and $9 \%$ in the control group, moreover it was more frequent among $C$. difficilepositive subjects $(p=0.05)$. Therefore, previous antibiotic use was shown to have a connection to toxigenic $C$. difficile positivity, but other assessed factors did not predict the presence of $C$. difficile toxins.

Patients in whom $C$. difficile toxins had been detected in the relapse group were treated with metronidazole. A combination of antibiotics was used, or a substitute was used for metronidazole (rifaximin or vancomycin) in case of metronidazole inefficiency, or if repeated stool exami- nations continued to be positive. Ciprofloxacin and metronidazol combination was used in case of suspicions natural relapse of CD (5 patients). Antibiotic switch was needed in $18.8 \%$ of $C$. difficile positive cases in relapsing group (50\% to vancomycin). Three patients needed hospitalisation in a Department of Infectious Diseases due to a therapy-resistant case of $C$. difficile positivity. However, the reasonable administration of a supplementary therapy or a modification of the maintained treatment was sufficient in $45.1 \%$ of the cases (oral or topical corticosteroids, 5-ASA and anti-TNF-therapy). Twenty two subjects required hospitalisation because of a relapse. Hospitalisation rate was not associated with initial level of FC or MMP-9 in natural relapse or in $C$. difficile positive cases.

\section{Long-term outcome}

The mean follow-up period was 51 (SD 8.2) months in our study. Toxigenic $C$. difficile positivity recurrence rate was $4.4 \%$. The hospitalisation rate was $54.8 \%$ during follow-up period, within that hospitalisation due to IBD was $39.2 \%$, due to $C$. difficile was $2.2 \%$ and due to other reasons was $31.8 \%$. More patients with relapse needed hospitalisation during follow-up period ( $\mathrm{P}=0.002)$ than patients in remission. Despite that, value of FC and MMP-9 did not predict the need of hospitalisation. The rate of hospitalisation due to any reason during follow-up period was $54.4 \%$ in C. difficile positive group and $55 \%$ in C. difficile negative group therefore $C$. difficile positivity itself did not predict need of hospitalisation on long-term period. On the other hand, hospitalisation during follow-up due to IBD was $45.4 \%$ and $35 \%$ in C. difficile positive and negative group, respectively. Colectomy rate during follow-up was $11.8 \%$. 


\section{Laboratory Findings}

The mean values of CRP in the relapse and the control group were $23.08 \mathrm{mg} / \mathrm{L}$ (in the range of: 1 to $202.6 \mathrm{mg} / \mathrm{L}$ ) and $6.46 \mathrm{mg} / \mathrm{L}$ (in the range of: 1 to $40.8 \mathrm{mg} / \mathrm{L}$ ), respectively. CRP was slightly higher in those with CD than in those with UC (the mean values of which are: CD: 25.17 $\mathrm{mg} / \mathrm{L}$ vs. UC: $21.31 \mathrm{mg} / \mathrm{L}$ ) in relapse group, but on the other hand, this difference was similar in the control group (the mean values of which are: CD: $9.68 \mathrm{mg} / \mathrm{L}$ vs. UC: 4.12 $\mathrm{mg} / \mathrm{L})$. The mean values of the leukocyte and the thrombocytes count, the serum iron and the hematocrit levels were $9.79 \mathrm{G} / \mathrm{L}, 326.05 \mathrm{G} / \mathrm{L}, 11.48 \mu \mathrm{mol} / \mathrm{L}$ and $39 \%$ in the relapse group, and 7.4 G/L, $292.7 \mathrm{G} / \mathrm{L}, 15.1 \mu \mathrm{mol} / \mathrm{L}$ and $40 \%$ in the control group (Table 2.).

\section{Faecal Calprotectin Levels}

The median value of FC in those in relapse $(640 \mu \mathrm{g} / \mathrm{g}$, in range $29-14000 \mu \mathrm{g} / \mathrm{g}$ ) was significantly higher compared to the control group (79 $\mu \mathrm{g} / \mathrm{g}$, in range $29-860 \mu \mathrm{g} / \mathrm{g}$ ) $(\mathrm{P}<0.001)$. FC did not showed difference in relapsing patients without (with the median value of: $510 \mu \mathrm{g} / \mathrm{g}$ ) vs. with C. difficile positivity (with the median value of: $690 \mu \mathrm{g} / \mathrm{g}$ ).

\section{Faecal MMP-9 Levels}

Similarly to FC, faecal MMP-9 levels were higher in the relapse group (11.36 ng/mL; in the range of: 0 to 168.79 $\mathrm{ng} / \mathrm{ml}$ ) compared to the control group $(5.61 \mathrm{ng} / \mathrm{mL}$; in the range of: 0 to $23.28 \mathrm{ng} / \mathrm{mL} ; \mathrm{P}=0.001$ ). We found obvious numerical difference between the mean values in cases of microbiological (C. difficile or Candida spp.) positive (mean: $8.0 \mathrm{ng} / \mathrm{ml}$ ) and negative cases (mean: $14.97 \mathrm{ng} / \mathrm{ml}$ ) in the relapse cohort; however, statistical analysis did not confirm the difference.

\section{Discussion}

Enteral infection rate during an IBD relapse, the clinical utility of faecal inflammatory markers (FC and MMP-9) and long-term outcome after presence of toxigenic $C$. difficile were assessed in this study. The occurrence of toxigenic $C$. difficile positivity was remarkably high in our IBD patients $(42.2 \%)$ compared to data of previous studies. Incidence was even higher in cases of relapse, suggesting some connection between flare-ups of IBD and C. difficile positivity. A differential diagnosis of a relapse of IBD and C. difficile infection is difficult in some cases; furthermore, both can occur at the same time, thus a faecal microbiological examination and tests for both toxins $A / B$ is recommended in the event of a relapse, as the evidence-based consensus of ECCO also suggests (3).

Some studies suggest that the aetiology of IBD with altered intestinal microbiome is a result of innate genetic defects in the intestinal epithelial and mucosal barriers. In addition, the aetiological background may involve a microbial imbalance in the intestine or dysfunction in the intestinal inflammatory cascade, leading to pathologic proliferation of cytokines (4). Although an exact aetiology of IBD has not been confirmed yet, the importance of microorganisms in the intestine is obvious. Toxigenic $C$. difficile positivity (53.8\%) and Candida (9.9\%) colonization were the most frequent results of faecal microbiological examinations in our relapse cohort, suggesting an imbalance of intestinal microflora.

It is well-known that the infection rate in patients with an IBD is greater than in the normal population; infectious agents are involved in the etiopathogenesis, but it can also initiate a relapse of the IBD (15). IBD is an independent risk factor of $C$. difficile positivity, mainly UC patients are susceptible to infection, and thus microorganisms have considerable significance in patient management $(3,18-20)$. In our study, the UC/CD ratio in the $C$. difficile cohort was approximately equal ( 25 UC vs. 23 CD subjects).

The disease course of a $C$. difficile infection can be extremely serious, even life-threatening complications may occur, which is confirmed beyond a doubt by the mortality rate of hospitalised IBD patients with a $C$. difficile infection (21). C. difficile infection was not severe in most of the cases in our study, serious complications did not occur during the tenure of the study. However, hospitalisation was needed in 13 of 49 cases with positive result of toxigenic C. difficile in relapsing group, most of them because of a severe flare-up requiring intravenous treatment. It seems that toxigenic $C$. difficile positivity is also a trigger and an additive factor in relapse of IBD. Hospitalisation, colectomy and mortality rates are higher in a population with toxigenic C. difficile positivity (12). In our study was confirmed that hospitalisation rate was higher in C. difficile infections, but we did not find any relationship on long-term period. In some studies, antimicrobial and immunomodulator agent-exposure has been shown to increase the possibility of a $C$. difficile infection and carriage (11). Basically, any type of antibiotic may be linked with the manifestation of a C. difficile infection; however, the antibiotics most commonly connected to an occurrence $C$. difficile infection include penicillins, clindamycin, cephalosporins and fluoroquinolones (22). Regardless, antibiotic use for IBD patients in general seems to be a critical risk factor for the development of a $C$. difficile positivity infection, as our results showed. The use of immunomodulators specifically has not been confirmed in our study to be predictive of a $C$. difficile positivity risk, however. The data available on immunomodulators is conflicting; some studies showed an increasing risk for $C$. difficile positivity (11), although others did not confirm these results (23). The number of toxigenic C. difficile-positive subjects taking immunosuppressants did not differ substantially compared to those patients not treated with immunosuppressants in our study. A correlation between $C$. difficile positivity and the use of gastric acidsuppressive agents, especially histamine blockers and proton pump inhibitors, has been suggested (24). However, similarly to our own findings, other observational studies did not yield results to support the connection (25).

A strong correlation between intestinal inflammation and FC has been confirmed in IBD (26); to note, its value can increase in enteral infections also (27). Enhanced levels of MMP-9 have been observe in the intestinal tissue in the case of IBD and seem to be actively involved in the inflammatory and remodelling process (28). In this study, levels 
of FC and MMP-9 were measured both in cases of infection and non-infection. Although we discover higher levels of FC and faecal MMP-9 in natural relapses than in infectioninduced relapses, the statistical analysis did not confirm this observation.

Colonising microbes inhabiting the intestinal mucosa are important for normal intestinal function and homeostasis. Dysbiosis develops when the composition of intestinal microbiome is unfavourable, and this condition may lead to various diseases. Altered microbiome may be a cause or consequence of a disease, but it may develop parallel with an abnormal condition (29). The balance of intestinal homeostasis is a sensitive system of intestinal microbiota, epithelium and immune cells (30). An alteration of colonic microbiota has been suggested in IBD (31), given that intestinal flora is altered in patients who relapse, which in turn allows the unopposed proliferation of $C$. difficile and Candida. The frequency of the community-acquired $C$. difficile infection has been increasing worldwide with incidence rates of 3 to $40 \%$ (10-12). Candida was presented in 9.9\% among the enrolled subjects. Presence of Candida in gastrointestinal tract is commonly benign, but in susceptible individuals with low level of inflammation (eg. IBD) may promote colonisation that promotes further inflammation, thus may become a trigger factor (32). The role of C. difficile may be the similar. Our data showed $42.2 \%$ of occurrences of $C$. difficile positivity in IBD outpatients, and $53.8 \%$ of the patients in the relapse cohort were $C$. difficile toxin positive. We revealed a significant difference regar- ding $C$. difficile positivity between IBD patients in relapse and those in remission. The occurrences of toxigenic $C$. difficile and Candida positivity were excessively high in our patients in an acute relapse, which suggests the importance of intestinal microbiota in IBD; therefore, in conclusion we recommend a faecal microbiological examination in every relapse to optimise therapy.

Acknowledgements, supports: This work was supported by the Research Grant of University of Szeged (No. 5S424), by the research grants of the National Research, Development and Innovation Office (Grant ID: FK-129266), and Research Foundation of University of Szeged Hetényi Géza Research Grant (No. 5S581).

Institutional review board statement: This study was reviewed and approved by review board of 1st Department of Medicine, University of Szeged.

Conflict-of-interest statement: The authors declare, to the best of our knowledge, no conflict of interest exists.

Data sharing statement: No additional data are available. Specific author contributions: study design and manuscript preparation: Anita Bálint, Urbán Edit, Klaudia Farkas, Tamás Molnár; statistical analysis and interpretation of the data: Anita Bálint, Tamás Molnár, Mónika Szűcs, Edit Urbán; patient selection, data collection and patient follow-up: Renata Bor, Zoltan Szepes, Ferenc Nagy, Mariann Rutka, Ágnes Milassin, Tamás Molnár; critical revision of the article for important intellectual content and final approval of the article: Tamás Molnár.

\section{Irodalom}

1. Stange EF, Travis SPL, Vermeire S, Reinisch W, Geboes K, Barageuskiene A, Feakins R, Fléjou JF, Herfarth H, Hommes DW, Kupcinskas, Lakatos PL, Mantzaris GJ, Schreiber S, Villanacci V, Warren BF; European Crohn's and Colitis Organisation (ECCO). European evidence-based Consensus on the diagnosis and management of ulcerative colitis: Definitions and diagnosis. JCC 2008; 2(1): 1-23 (PMID: 21172194 DOI: 10.1016/j. crohns.2007.11.001.)

2. Van Assche G, Dignass A, Panes J, Beaugerie L, Karagiannis J, Allez M, Ochsenkühn T, Orchard T, Rogler G, Louis E, Kupcinskas L, Mantzaris G, Travis S, Stange E; European Crohn's and Colitis Organisation (ECCO). The second European evidence-based consensus on the diagnosis and management of Crohn's disease: Definitions and diagnosis. JCC 2010; 4(1): 7-27. (PMID: 21122488 DOI: 10.1016/j.crohns.2009.12.003.)

3. Rahier JF, Ben-Horin S, Chowers Y Conlon C, De Munter P, D'Haens G, Domènech E, Eliakim R, Eser A, Frater J, Gassull M, Giladi M, Kaser A, Lémann M, Moreels T, Moschen A, Pollok R, Reinisch W, Schunter M, Stange EF, Tilg H, Van Assche G, Viget N, Vucelic B, Walsh A, Weiss G, Yazdanpanah Y, Zabana Y, Travis SP, Colombel JF; European Crohn's and Colitis Organisation (ECCO). European evidence-based Consensus on the prevention, diagnosis and management of opportunistic infections in inflammatory bowel disease. JCC 2009; 3: 47-91. (PMID: 21172250 DOI: 10.1016/j.crohns.2009.02.010.)

4. Kaur N, Chen CC, Luther J, Kao JY. Intestinal dysbiosis in inflammatory bowel disease. Gut Microbes 2011; 2(4): 211-216. (PMID: 21983063 DOI: 10.4161/gmic.2.4.17863.)

5. Machiels K, Joossens M, Sabino J, De Preter V, Arijs I, Eeckhaut V, Ballet V, Claes K, Van Immerseel F, Verbeke K, Ferrante M, Verhaegen J, Rutgeerts $\mathrm{P}$, Vermeire $\mathrm{S}$. A decrease of the butyrate-producing species Roseburia hominis and Faecali bacterium prausnitzii defines dysbiosis in patients with ulcerative colitis. Gut 2014; 63(8): 1275-1283. (PMID: 24021287 DOI: 10.1136/gutjnl-2013-304833.)

6. Knights D, Lassen KG, Xavier RJ. Advances in inflammatory bowel disease pathogenesis: linking host genetics and the microbiome. Gut 2013 62(10): 1505-1510. (PMID: 24037875 DOI: 10.1136/gutjnl-2012-303954.)

7. Pruitt RN, Borden LD. Toward a structural understanding of Clostridioides difficile toxins A and B. Front in Cell Infect Microbiol 2012; 2: 28. (PMID: 22919620 DOI: 10.3389/fcimb.2012.00028)

8. Honda H, Dubberke ER. The changing epidemiology of Clostridioides difficile infection. Curr Opin Gastroenterol 2014; 30(1): 54-62. (PMID: 24285002 DOI: 10.1097/MOG.0000000000000018.)

9. Kazanowski M, Smolarek S, Kinnarney F, Grzebieniak Z. Clostridioides difficile: epidemiology, diagnostic and therapeutic possibilities-a systematic review. Tech Coloproctol. 2014; 18(3): 223-232. (PMID: 24178946 DOI: 10.1007/s10151-013-1081-0)

10. Bossuyt P, Verhaegen J, Van Asshe G, Rutgeerts P, Vermeire S. Increasing incidence of Clostridioides difficile-associated diarrhea in inflammatory bowel disease. J Crohns Colitis 2009; 3: 4-7. (PMID: 21172241 DOI: 10.1016/j.crohns.2008.09.003.)

11. Meyer AM, Ramzan NN, Loftus EV Jr, Heigh RI, Leighton JA. The diagnostic yield of stool pathogen studies during relapses of inflammatory bowel disease. J Clin Gastroenterol 2004; 38(9): 772-775. (PMID: 15365403) 12. Mylonaki M, Langmead L, Pantes A, Johnson F, Rampton DS. Enteric infection in relapse of inflammatory bowel disease: importance of microbiological examination of stool. Eur J Gastroenterol Hepatol 2004; 16(8): 775-778. (PMID: 15256979)

13. Hourigan SK, Oliva-Hemker M, Hutfless S. The prevalence of Clostridioides difficile infection in pediatric and adult patients with inflammatory bowel disease. Dig Dis Sci 2014; 59: 2222-7. doi: 10.1007/s10620-0143169-4

14. Harminder Singh, Zoann Nugent, B. Nancy Yu, Lisa M. Lix, Laura E. Targownik, Charles Bernstein. Higher Incidence of Clostridioides Difficile Infection Among Individuals With Inflammatory Bowel Disease. Gastroenterology 2017; 153(2): 430-438.e2. DOI: 10.1053/j.gastro.2017.04.044

15. Irving PM, Gibson PR. Infections and IBD. Nat Rev Gastroenterolo 2008; 5: 18-27. (PMID: 18174904 DOI: 10.1038/ncpgasthep1004.)

16. Gao Q, Meijer MJ, Kubben FJ, Sier CF, Kruidenier L, van Duijn W, van den Berg $M$, van Hogezand RA, Lamers $C B$, Verspaget HW. Expression of matrix metalloproteinases-2 and -9 in intestinal tissue of patients with inflammatory bowel diseases. Digestive and Liver Disease. 2005; 37: 584-592. (PMID: 15869913)

17. Annaházi A, Molnár T, Farkas K, Rosztóczy A, Izbéki F, Gecse K, Inczefi O, Nagy F, Földesi I, Szúcs M, Dabek M, Ferrier L, Theodorou V, Bueno L, Wittmann T, Róka R. Fecal MMP-9: A new noninvasive differential diagnostic and activity marker in ulcerative colitis. Inflamm Bowel Dis 2013; 19(2): 316-320. (PMID: 22550024 DOI: 10.1002/ibd.22996.)

18. Crobach MJT, Planche T, Eckert E, Barbut F, Terveer EM, Dekkers OM, Wilcox MH, Kuijper EJ. European Society of Clinical Microbiology and Infectious Diseases: update of the diagnostic guidance document for Clostridioides difficile infection. Clinical Microbiology and Infection 2016; 22: S63-S81.

További irodalom megtalálható a szerkesztőségben, valamint

a www.gastronews.olo.hu weboldalon. 